\title{
El inicio y la libertad de regulación de las actuaciones arbitrales
}

\section{The Start of the Arbitration Proceedings and the Parties' Freedom to Regulate Them}

Mario Castillo Freyre*, Rita Sabroso Minaya**, Laura Castro Zapata***, Jhoel Chipana Catalán****

http://dx.doi.org/10.21503/lex.v14i18.1237

* Mario Castillo Freyre, Magíster y Doctor en Derecho, Abogado en ejercicio, socio del Estudio que lleva su nombre; profesor principal en la Pontificia Universidad Católica del Perú. Miembro de Número de la Academia Peruana de Derecho. Director de las colecciones Biblioteca de Arbitraje y Biblioteca de Derecho de su Estudio. www.castillofreyre.com E-mail: estudio@castillofreyre.com

** Rita Sabroso Minaya, Abogada del Estudio Mario Castillo Freyre. Profesora de Arbitrajes Especiales en la Facultad de Derecho de la Universidad de Lima. Con estudios en la Maestría de Derecho de la Competencia y Propiedad Intelectual en la Pontificia Universidad Católica del Perú. E-mail: rsm@castillofreyre.com

*** Laura Castro Zapata, Abogada por la Universidad Femenina del Sagrado Corazón. Magíster en Derecho, con mención en Derecho Empresarial, por la Universidad de Lima. Ha concluido sus estudios en el Doctorado en Derecho de la Pontificia Universidad Católica del Perú. Dirige el área corporativa del Estudio Mario Castillo Freyre y también se desempeña como Árbitro. E-mail: lcz@castillofreyre.com

**** Jhoel Chipana Catalán, Abogado por la Pontificia Universidad Católica del Perú, Profesor en la Universidad de San Martín de Porres, Abogado en el Estudio Mario Castillo Freyre y Secretario Arbitral en procesos ad-hoc. E-mail: jcc@castillofreyre.com

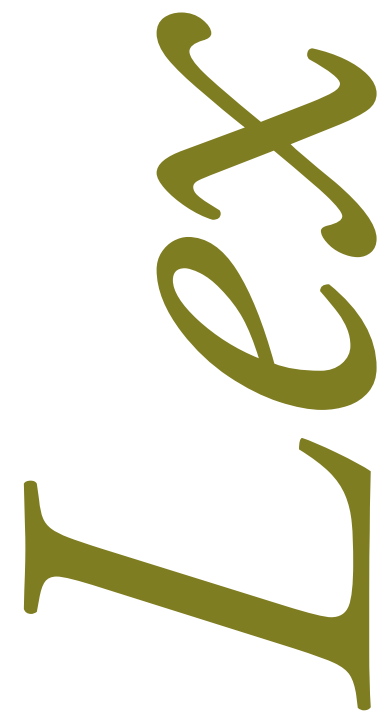




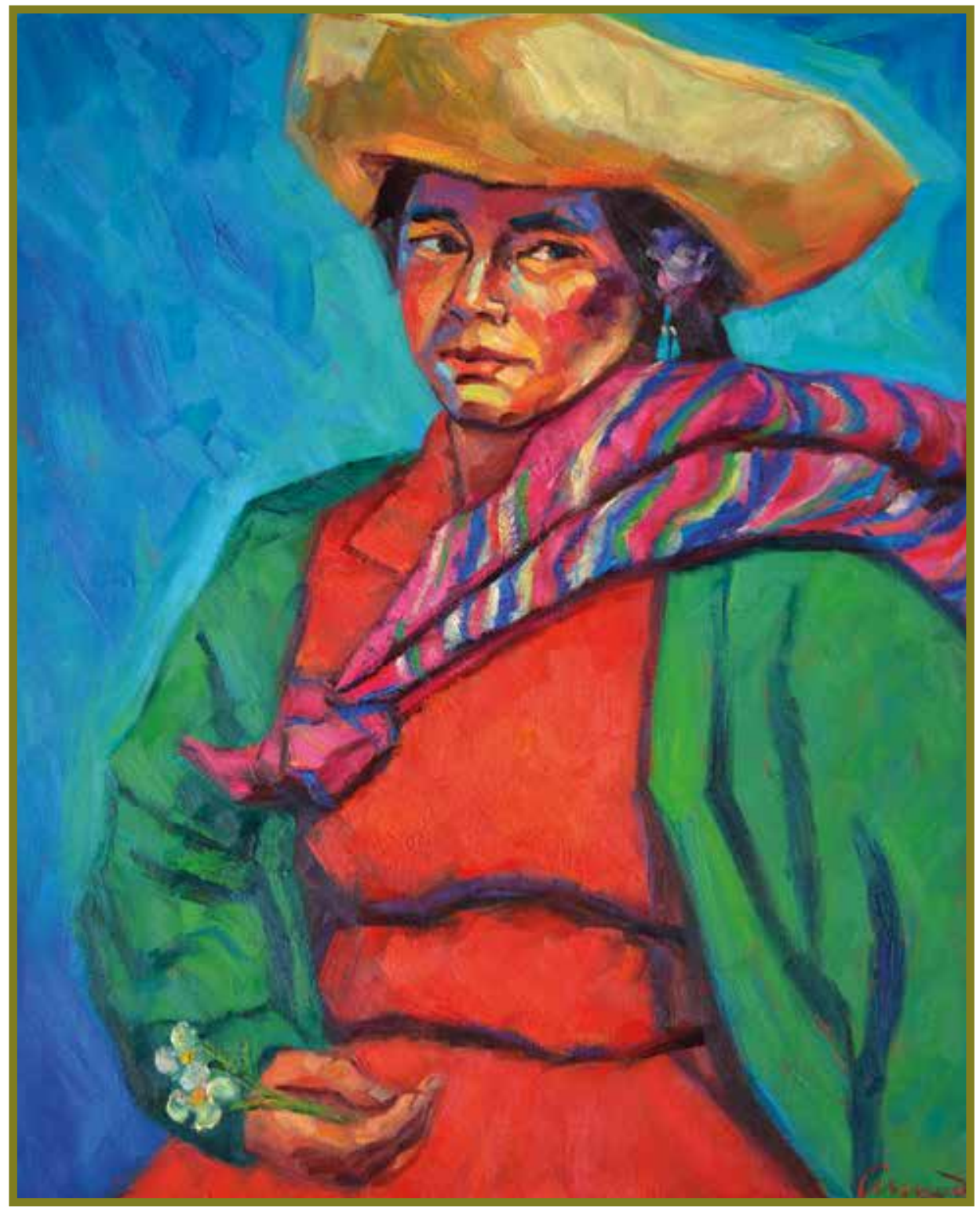

Natividad. Óleo sobre lienzo $(100 \mathrm{~cm}$ x $81 \mathrm{~cm})$. Ever Arrascue. 


\section{RESUMEN}

En este artículo, los autores abordan y analizan cuándo se inician las actuaciones arbitrales y el arbitraje, así como la libertad de las partes de regular las actuaciones arbitrales, de acuerdo con la Ley de Arbitraje peruana, Decreto Legislativo No 1071.

Palabras clave: arbitraje, inicio, regulación, proceso, actuaciones arbitrales.

\section{ABSTRACT}

The authors discuss and analyze in this paper when the arbitral proceedings and arbitrage begin, as well as the freedom of the parties to regulate the arbitral proceedings in accordance to the Peruvian Arbitration Law, Legislative Decree No. 1071.

Key words: arbitration, start, regulation, process, arbitration proceedings. 


\section{EL INICIO DEL ARBITRAJE}

El Título IV del Decreto Legislativo No 1071 (en adelante, la Ley de Arbitraje) aborda todo lo relativo a las actuaciones arbitrales. El artículo 33 define el inicio del arbitraje de la siguiente manera:

\section{Artículo 33.- Inicio del arbitraje}

Salvo acuerdo distinto de las partes, las actuaciones arbitrales respecto de una determinada controversia se iniciarán en la fecha de recepción de la solicitud para someter una controversia a arbitraje.

Este artículo señala que, salvo acuerdo distinto de las partes, las actuaciones arbitrales respecto de una determinada controversia se iniciarán en la fecha de recepción de la solicitud para someter una controversia a arbitraje.

Lo señalado por el numeral bajo estudio resulta de suma importancia, debido a que antes se tenía la duda en torno a cuándo se producía el inicio del arbitraje, es decir, si el inicio del arbitraje se producía cuando se instalaba el tribunal arbitral o cuando se presentaba la solicitud de arbitraje.

Diversos son los sistemas que existen sobre este particular. Así, por ejemplo, la Ley de Arbitraje y Conciliación boliviana señala que el procedimiento arbitral se iniciará cuando todos los árbitros hayan notificado a las partes por escrito su aceptación de la designación; asimismo, la Ley de Conciliación y Arbitraje de Honduras establece que el procedimiento arbitral se entiende iniciado cuando el último de los árbitros designados haya manifestado a las partes por escrito su aceptación del cargo. De otro lado, hay sistemas como el nuestro, o el de la ley española de arbitraje, que establecen que las actuaciones arbitrales respecto de una determinada controversia se iniciarán en la fecha de recepción de la solicitud para someter una controversia a arbitraje.

Hoy, para una serie de aspectos relativos a diversas materias contenidas en la propia Ley, se considera que el arbitraje se inicia con la solicitud para someter la controversia a arbitraje. 
García Calderón Moreyra ${ }^{1}$ señala que la parte que inicialmente recurre al arbitraje deberá notificar a la otra invocando su convenio arbitral, indicando una referencia a la cláusula que se invoca y al contrato del que surge la controversia, así como la pretensión que se demanda. En caso esté designado un instituto arbitral, se notificará también a este. Esta notificación sirve para informar que se recurre al arbitraje ya pactado y que se someterá a reclamación un problema concreto.

Algunos autores, ${ }^{2}$ que por cierto defienden la naturaleza jurisdiccional del arbitraje (doctrina de la que nosotros no formamos parte), señalan que lo que se inicia no es el arbitraje sino la relación jurídico-procesal respecto de una concreta controversia.

Creemos, junto a Vidal Fernández, ${ }^{3}$ que la fecha en que el demandado ha recibido el requerimiento de someter la controversia a arbitraje marca el momento a partir del cual los contendientes quedan comprometidos en el procedimiento arbitral, y con ella se establece una relación entre el demandante y el demandado por la cual se obligan a resolver su conflicto mediante arbitraje. De este modo, quedan fijadas las partes contendientes (quien requiere y el requerido) y la controversia. A partir de la delimitación subjetiva y objetiva de ese conflicto se inicia el método de resolución del mismo.

Ahora bien, creemos acertada la opinión vertida por Kundmüller Caminiti, ${ }^{4}$ cuando realiza un deslinde entre los términos proceso, procedimiento y actuaciones arbitrales.

Así, dice el citado profesor, que

la LA (Ley de Arbitraje) no se refiere al proceso arbitral ni al procedimiento arbitral, sino simplemente a las actuaciones arbitrales. Se produce un deslinde tácito con las nociones jurídicas de proceso o procedimiento. Nótese que en ambos casos los abogados entendemos que estamos ante contextos formales preestablecidos y regidos por el principio de legalidad que guía el funcionamiento del Estado. [...] Como es evidente, la autoridad de los árbitros no es equivalente a la autoridad de los jueces y de las autoridades administrativas. Por lo que no resulta conveniente usar la denominación proceso o procedimiento para referirse a las actuaciones arbitrales. [...] En el arbitraje nos encontramos ante un sistema de balances, pesos y contrapesos, que equilibran el íter a partir de lo pactado por las partes en el convenio arbitral y estando a lo decidido por los árbitros, en el marco del ordenamiento jurídico, [...] la autoridad estatal no es relevante en la conformación del íter arbitral. En todo caso, no lo es en la misma intensidad que en el proceso judicial o que en el procedimiento

Gonzalo García Calderón Moreyra, El arbitraje internacional (Lima: Cecosami, 2004), 137.

2 Munné Catarina, citada por Begoña Vidal Fernández, "Inicio del arbitraje", en Comentarios prácticos a la Ley de Arbitraje (Valladolid: Editorial Lex Nova, 2004), 489.

3 Begoña Vidal Fernández, "Inicio del arbitraje”, en Comentarios prácticos a la Ley de Arbitraje..., 489.

4 Franz Kundmüller Caminiti, "Inicio del arbitraje", en Comentarios a la ley peruana de arbitraje (Lima: IPA, 2011), tomo I, 384 y ss. 
administrativo, siendo su rol de carácter residual. [...] La denominación actuación, que remite finalmente a la idea de conjunto de autos o actuados, generalmente se refiere a una idea de actuaciones o piezas de un procedimiento judicial, y en nuestro caso, de un arbitraje.

Ahora bien, cabe precisar que la Ley de Arbitraje hace mención en todo su texto al término actuaciones y solamente en seis oportunidades se hace referencia a la palabra proceso, cinco de las cuales se remiten al proceso judicial y una (contenida en el artículo 47, numeral 2, inciso b) al proceso arbitral de manera equivocada, pues allí debió consignarse la referencia al término actuaciones arbitrales.

Por otro lado, Yáñez Velasco 5 habla sobre la forma del requerimiento, señalando que cuál es la forma del requerimiento supone una cuestión abierta. El legislador siquiera precisa la necesidad de una comunicación fehaciente — al menos con uso de mencionada terminología-, y mucho menos señala mecanismos rituarios concretos, lo que por demás parece ajustado a la libre forma del arbitraje como institución apoyada en la autonomía de voluntades. Cabría, en consecuencia, cualquier modo de comunicación o aquel que los propios interesados hubieran concretado en el convenio arbitral. Pero en virtud del interés del sujeto comunicante conviene la constancia del requerimiento, aunque no sea escrita necesariamente, pues si el requerido niega haberlo sido (imagínese la vía telefónica), es el requiriente quien tendría que probar la comunicación efectuada y su contenido.

Finalmente, cabe recordar que estamos ante una norma de carácter dispositivo, ya que esta empieza su redacción con la frase "salvo acuerdo distinto de las partes". Una vez más, pues, la Ley reafirma el principio del libre ejercicio de la voluntad de las partes en todo arbitraje, ya que serán estas quienes pueden modificar el momento de inicio del arbitraje mediante un pacto o, si es que se encuentra involucrada la administración de una institución arbitral, será esta la que pueda modificarlo a través de su respectivo reglamento. Las partes o la institución podrán decidir que el arbitraje se inicie antes o después del momento señalado por la Ley de Arbitraje.

\section{LA LIBERTAD DE REGULACIÓN DE LAS ACTUACIONES ARBITRALES}

Este tema se encuentra regulado en el artículo 34 de la Ley de Arbitraje:

\section{Artículo 34.- Libertad de regulación de actuaciones}

1. Las partes podrán determinar libremente las reglas a las que se sujeta el tribunal arbitral en sus actuaciones. A falta de acuerdo o de un reglamento arbitral aplicable, el tribunal arbitral decidirá las reglas que considere más apropiadas teniendo en cuenta las circunstancias del caso.

5 Ricardo Yáñez Velasco, Comentarios a la nueva Ley de Arbitraje (Valencia: Tirant lo Blanch, 2004), 519- 520. 
2. El tribunal arbitral deberá tratar a las partes con igualdad y darle a cada una de ellas suficiente oportunidad de hacer valer sus derechos.

3. Si no existe disposición aplicable en las reglas aprobadas por las partes o por el tribunal arbitral, se podrá aplicar de manera supletoria las normas de este Decreto Legislativo. Si no existe norma aplicable en este Decreto Legislativo, el tribunal arbitral podrá recurrir, según su criterio, a los principios arbitrales así como a los usos y costumbres en materia arbitral.

4. El tribunal arbitral podrá, a su criterio, ampliar los plazos que haya establecido para las actuaciones arbitrales, incluso si estos plazos estuvieran vencidos.

El inciso 1 del artículo 34 de la Ley de Arbitraje en actual vigencia, establece que las partes podrán determinar libremente las reglas a las que se sujete el tribunal arbitral en sus actuaciones. A falta de acuerdo o de un reglamento arbitral aplicable, el tribunal arbitral decidirá las reglas que considere más apropiadas, teniendo en cuenta las circunstancias del caso.

A simple vista, no parecería haber mayor problema en llegar a un arbitraje. Porque en materia de derecho civil, una vez permitido el arbitraje por la ley, la celebración de un contrato que lo acuerde debería ser, en teoría, la cosa más fácil del mundo.

El problema es que lo que en la teoría del sentido común es tan simple como este, en la doctrina tradicional del arbitraje no. Aquí, la complejidad es el denominador común, y la simplicidad, la excepción.

Si hubiera que ponerlo literariamente, el alumbramiento de un arbitraje viene precedido de un embarazo complejo. Es más, y siempre en términos literarios, la concepción misma del futuro arbitraje no está atada a la naturaleza de un solo método. Más de un camino es el que lleva al arbitraje, lo que es lo mismo a decir que, ya en términos contractuales, no existe una sola forma de contratar un arbitraje.

En el tráfico jurídico y comercial de todos los días, los arbitrajes se contratan, casi con absoluta mayoría, en lo que se conoce como convenio arbitral, que es pues un contrato en toda línea. En este contrato las partes se obligan inequívocamente a sustraerse de la jurisdicción del Estado para someterse a una jurisdicción privada determinada por ellas, con el fin de resolver un hipotético conflicto de intereses que pudiera suscitarse de una relación jurídica existente entre ambas, esto es, casi para todos los efectos de la vida diaria, otro contrato del que el arbitral forma parte. ${ }^{6}$

6 Cfr. Mario Castillo Freyre y Ricardo Vásquez Kunze, Arbitraje. El juicio privado: la verdadera reforma de la Justicia, Biblioteca de Arbitraje del Estudio Mario Castillo Freyre (Lima: Palestra Editores-Estudio Mario Castillo Freyre, 2006), vol. 1,54 y ss. 
Contratado el arbitraje a través del convenio arbitral y cumplida la condición para que la obligación sea exigible, es decir, producida la controversia que impele a las partes a resolverla arbitralmente, se suceden en el tiempo una serie de contratos en estrecha relación con el arbitral y cuyos propósitos son, precisamente, que la obligación asumida por las partes en el convenio arbitral quede satisfecha. En otras palabras, para que el arbitraje contratado se materialice, se revele en los hechos, son necesarios otros contratos accesorios a su vez al celebrado en la cláusula arbitral o contrato de arbitraje.

Así pues, ¿cómo se contratan los árbitros?, ¿cómo al eventual presidente del tribunal?, ¿Cómo las reglas que regirán el proceso? Ciertamente no a través del contrato arbitral celebrado en la cláusula como muchas veces, sin hacer distinción alguna, se confunde. Porque una cosa es la relación contractual entre las partes de la que solo puede derivar el contrato arbitral, y otra muy distinta la relación contractual de las partes con terceros que, eventualmente, contribuirán ejerciendo una función jurisdiccional para que ese contrato arbitral celebrado exclusivamente entre las partes se cumpla.

En principio, la relación entre las partes y los terceros que tendrán participación en el proceso arbitral se manifiesta, en nuestro criterio, a través de dos modalidades contractuales nominadas: la locación de servicios y el mandato. La primera, necesaria. La segunda, no.

De otro lado, como sabemos, las reglas en el proceso arbitral se determinan en dos momentos muy marcados. El primero de ellos es el convenio arbitral.

En el convenio arbitral se establecerá la naturaleza del arbitraje, o sea, si el arbitraje es de derecho o es de conciencia. Se determinará, además, si se trata de un arbitraje ad hoc o de un arbitraje institucional; se determinará el número de árbitros, etc. Es decir, hay un marco general en la Ley de Arbitraje que impone determinadas reglas de orden público y una serie muy grande de normas de orden dispositivo, dentro del cual pueden girar las partes al determinar las reglas a las que se sujetará el tribunal arbitral.

Ese contrato, luego se va a ver enriquecido, complementado y tal vez modificado o regulado por un segundo contrato que celebran las partes con los árbitros, en el acta de instalación del tribunal arbitral.

En esa acta podrán establecerse reglas complementarias, algunas de las cuales —inclusopodrían alterar los términos del propio convenio arbitral.

Esta alteración puede producirse de manera expresa o de manera tácita, en la medida en que las reglas resulten incompatibles con las reglas anteriores, a efectos de lo cual se aplican las normas sobre manifestación tácita de voluntad, contenidas en el universo jurídico del Código Civil. 
En este sentido, cuando se trata de arbitrajes institucionales, es necesario señalar que se aplicarán las normas del Reglamento Arbitral que sea aplicable en el caso concreto. Además, las partes se habrían sometido al mismo, al pactar, precisamente, un arbitraje institucional.

Ahora bien, ¿qué pasaría en el supuesto en el cual no exista un reglamento arbitral aplicable, es decir, que no se trate de un arbitraje institucionalizado?

En este caso, señala el artículo 34, inciso 1 del Decreto Legislativo No 1071, que el tribunal arbitral decidirá las reglas que considere más apropiadas, teniendo en cuenta las circunstancias del caso.

Sobre el particular es indispensable decir que cuando hablamos de un supuesto como este, se tratará de un arbitraje ad hoc; y en el arbitraje ad-hoc, el tribunal arbitral establecerá determinadas reglas con absoluta libertad, pero esas reglas tienen que ser establecidas dentro del marco imperativo del convenio arbitral, salvo que las partes acuerden expresa o tácitamente modificarlo, y bajo el marco de las normas imperativas del Decreto Legislativo No 1071 y la Constitución Política del Estado.

Sobre este punto, Kundmüller Caminiti ${ }^{7}$ señala que la libertad de las partes es inherente a las libertades individuales reconocidas y protegidas constitucionalmente en el ordenamiento jurídico, siendo este justamente el espacio de regulación inherente al arbitraje, a lo que se suma la necesidad, tal como está normado en la norma constitucional peruana, de regular el arbitraje del Estado.

Es decir, esta libertad de regulación que se otorga a las partes y al tribunal arbitral no se deberá entender como una regulación que se encuentre fuera del marco normativo del convenio arbitral, la Ley de Arbitraje o las normas constitucionales.

En esta misma línea de pensamiento, debemos recalcar que las partes pueden hacer aplicables un conjunto de normas preexistentes o redactarlas ellas mismas. En la práctica es raro que las partes realicen un código completo que regirá el procedimiento arbitral. Únicamente algunos aspectos específicos al caso son abordados en forma especial o constituyen la materia de un acuerdo específico; el resto, por lo general, es regulado por referencia a reglas arbitrales o derecho arbitral. ${ }^{8}$

Es necesario reparar también en la expresión que contiene el inciso 1 del artículo 34 de la Ley, cuando señala que el tribunal arbitral decidirá las reglas que considere más apropiadas, teniendo en cuenta las circunstancias del caso.

7 Franz Kundmüller Caminiti, "Libertad de regulación de actuaciones”, en Comentarios a la ley peruana de arbitraje..., 392.
8 En este mismo sentido se pronuncia Francisco González de Cossío, Arbitraje (México: Editorial Porrúa, 2008), 212. 
Esto es importante en la medida de que, siempre teniendo en cuenta lo anterior, se deja un margen de libertad al tribunal arbitral, para adecuar esas reglas, precisamente, a la naturaleza de la controversia o de la futura controversia, a lo que las partes han decidido en el convenio arbitral y, en general, a otras circunstancias que puedan conducir a que el tribunal establezca determinadas reglas y deje de lado algunas otras.

De otro lado, el inciso 2 del artículo 34 de la Ley de Arbitraje señala que el tribunal arbitral deberá tratar a las partes con igualdad y dar a cada una de ellas suficiente oportunidad de hacer valer sus derechos.

Los principios consagrados en este inciso resultan imprescindibles en todo proceso, ya sea que estemos ante un proceso seguido ante tribunales ordinarios, arbitrales o de cualquier otra naturaleza.

La administración de justicia se rige necesariamente por reglas de contradicción y de igualdad. Las reglas de igualdad de trato en el arbitraje implican no solo la imparcialidad debida de los árbitros, tema sobre el cual ya nos hemos pronunciado, sino además que las reglas rijan por igual a las partes inmersas en el proceso.

Este es un tema importantísimo que nunca puede obviarse a lo largo del proceso. Sin embargo, en esta oportunidad vamos a postular algunas ideas que uno de los autores de este trabajo desarrolló anteriormente junto a Ricardo Vásquez Kunze, ${ }^{9}$ y que constituyen una mirada diferente a los temas planteados.

Si bien la materia prima de la mayoría de los procesos es la existencia de un conflicto de intereses, de una controversia que la sociedad quiere y manda que se resuelva en el estado de derecho, esta no puede producirse sino encarnada en las partes. No hay controversia si no hay partes, sin un hombre o una institución que tengan una versión contraria a la de otro hombre o institución y que genere, a su vez, un litigio. Así pues, un proceso arbitral es, por lo menos, un asunto entre dos partes que buscan justicia. A esto se le conoce como el principio de dualidad de posiciones. ${ }^{10}$

Nótese sin embargo que este principio por el cual se quiere dejar establecida la existencia de dos partes que, hallándose en conflicto por un asunto determinado, ponen en marcha la maquinaria de la justicia privada dando vida a un proceso arbitral, no es privativo de los

9 A mayor abundamiento revisar la obra de Mario Castillo Freyre y Ricardo Vásquez Kunze. Arbitraje. El juicio privado: la verdadera reforma de la justicia (Lima: Palestra, Cátedra Garrigues y Estudio Mario Castillo Freyre, 2007), 206 y ss.

10 En función al protagonismo e importancia de las partes en el arbitraje, Ana María Chocrón considera que existen principios relativos a las partes, que pueden dividirse en: a) El principio de dualidad de posiciones; b) La proyección del principio de igualdad de las partes en el arbitraje; y, c) La proyección del principio de buena fe de las partes en el arbitraje. Ver Ana María Chocrón Giráldez, Los principios procesales del arbitraje (Barcelona: J. M. Bosch Editor, 2000), 69-82. 
conflictos, sino también de los acuerdos. En efecto, pues antes de llegar al proceso arbitral por el cual habrá de resolverse una controversia cuya existencia requiere de por lo menos dos partes controvertidas, dos partes también han tenido que ponerse de acuerdo, o, mejor dicho, contratar un arbitraje para resolver una controversia ya existente o una por existir. Así pues, en el caso del arbitraje, el principio de dualidad de posiciones informa tanto de los acuerdos como de los desacuerdos, siendo que los acuerdos fundan, con el sometimiento a la jurisdicción arbitral, la solución de los desacuerdos.

Esto, empero, no es percibido así por un sector de la doctrina que parece circunscribir, erradamente el principio de dualidad de posiciones únicamente a los desacuerdos entre las partes que habrá de resolver un proceso arbitral. Se dice así que el principio de dualidad de posiciones es el sustrato de la contraposición y posterior contradicción de las partes en el arbitraje. $^{11}$

Este error se origina en lo que se suele entender por dualidad de posiciones, diferenciando este concepto del de dualidad de partes. ${ }^{12}$ Existiría así dualidad de posiciones solo si dos partes tienen dos posiciones encontradas. Por el contrario, no habría dualidad de posiciones si, por más de que existieran dos partes, sus posiciones fueran “iguales”. En realidad, no puede haber diferencia entre dualidad de partes y dualidad de posiciones, así como tampoco podría haberla entre pluralidad de partes y pluralidad de posiciones. Y no la puede haber porque las posiciones se encarnan en las partes, son manifestaciones de su voluntad y, por tanto, son consustanciales a ellas. Así pues, habrá tantas posiciones como partes haya. Y ninguna posición será "igual" que la otra en tanto ninguna parte puede ser igual que las otras. Que la posición de Marx coincida con la de Engels no significa que Marx y Engels sean la misma persona, porque solo siéndolo, su posición podría ser igual. Las posiciones siempre serán distintas, aunque coincidan, porque tanto Marx como Engels son personas absolutamente diferentes. No es pues la posición la que determina la existencia de las personas, sino las personas las que determinan la existencia de sus posiciones.

11 Siguiendo a la doctrina tradicional, Ana María Chocrón entiende el principio de dualidad de posiciones como el pilar de la contraposición y posterior contradicción de las partes. Sostiene que para que pueda constituirse válidamente un proceso arbitral es necesaria la presencia de dos posiciones que, necesariamente también, deben estar enfrentadas. En este sentido agrega que, a pesar de que la Ley de Arbitraje española no contiene la terminología de demandante y demandado, ello no implica que el arbitraje carezca de litigiosidad, en la medida de que lo que se discute en el proceso arbitral implica una contienda entre las partes. La dualidad de posiciones implica entonces, en el arbitraje, intereses enfrentados o que las partes presumen que los habrá, los que posteriormente entrarán en contradicción. Ver Ana María Chocrón Giráldez, Los principios procesales del arbitraje...

12 El profesor Juan Montero Aroca considera, precisamente, que se debe distinguir entre dualidad de partes y dualidad de posiciones, en la medida de que si no puede existir un proceso con una sola parte, sí puede darse con más de dos partes. En este sentido, según él, en el proceso con pluralidad de partes se mantiene el principio de dualidad de posiciones, a pesar de existir más de dos partes con plenitud de derechos, cargas y deberes procesales. Ver Juan Montero Aroca, Introducción al Derecho Procesal (Madrid: Ediciones Tecnos, 1976), 236-237. 
Por eso, nosotros consideramos que es mucho mejor hablar de posiciones coincidentes y posiciones disidentes. Solo en este último caso, el del disenso, entenderíamos que el así llamado principio de dualidad de posiciones funde la contraposición y contradicción de las partes. Y esto es obviamente así si por arbitraje se entiende solo el proceso arbitral.

En realidad, el principio de dualidad de posiciones es un concepto neutro, que de lo único que nos informa es que para la existencia de acuerdos o desacuerdos deben existir a su vez al menos dos partes que estén de acuerdo o en desacuerdo. Y en el arbitraje, como hemos visto, el principio se manifiesta en ambos: en los acuerdos entre dos partes que deciden contratar un arbitraje para resolver desacuerdos presentes o futuros, y en los desacuerdos que se resolverán concretamente en un proceso arbitral.

Así pues, cuando se trata del primer caso, es decir, cuando el principio de dualidad de posiciones se manifiesta en los acuerdos, es absurdo sostener que este funde la contraposición y contradicción de las partes. Todo lo contrario. En este caso lo que funda es la convergencia en vez de la contraposición y la coherencia en vez de la contradicción. Solo así dos partes pueden contratar un arbitraje.

De suyo va que también se necesitan dos para una controversia y que, por lo tanto, el principio de dualidad de posiciones anima también cualquier proceso donde estas controversias tengan que ser resueltas. Pero aquí hay que ser muy precisos. Pues como se colige de lo antedicho, una cosa es la manifestación de una controversia y otra muy distinta el proceso de su solución legal. ${ }^{13}$

Y es más, como habíamos advertido, la solución jurídica a esta dualidad de posiciones controvertidas pasa, en el caso del arbitraje, por la dualidad de posiciones convergentes de encauzar las controvertidas en un proceso arbitral. Es recién cuando las partes en conflicto se ponen de acuerdo en querer el proceso arbitral para dirimir sus controversias, que el principio de dualidad de posiciones controvertidas o disidentes opera como una contradicción entre las partes, en la medida de que, ante una autoridad investida por las partes con poderes para juzgar, estas contradicen recíprocamente los hechos y derechos que cada una alega. Contradice pues una parte la posición de la otra y viceversa. Y siempre se contradice ante alguien, ante alguien que tenga las calidades jurisdiccionales y que pueda decir a qué parte le asiste o no el derecho. He ahí la diferencia entre contradicción y controversia o contraposición de intereses. La primera necesita de dos partes con intereses contrapuestos, es cierto, pero de un tercero que los dirima de acuerdo a ley. La segunda, la controversia, solo necesita de dos partes contrapuestas.

13 “[...] mientras la contraposición alude a la situación o posición de las partes con intereses contrapuestos, es decir, a la controversia misma, la contradicción hace referencia a la actuación de las mismas dentro del proceso, de forma que puedan rebatirse y cruzar sus respectivas alegaciones y pruebas, lo cual concierne al órgano articularlo". Ana María Chocrón Giráldez, Los principios procesales del arbitraje..., 71. 
Esa es la razón por la cual nos hemos negado a seguir a un sector de la doctrina que estatuye como uno de los principios rectores de dicho proceso la dualidad de posiciones. Tal como hemos podido demostrar, este es un principio impreciso, conceptualmente hablando. Nosotros hemos optado por el más preciso principio de contradicción de posiciones que, además, solo puede darse, como hemos visto, en el proceso arbitral.

Otro de los principios relacionados con las partes que anima un proceso arbitral es el que la doctrina conoce como principio de igualdad de las partes. Pero, ¿qué debe entenderse por este principio? ¿Acaso que las partes son iguales? ¿Que tienen tal vez derechos y obligaciones iguales? ¿Que sus oportunidades son iguales para hacer valer sus derechos o demostrarlos en el proceso arbitral? La doctrina parece responder a todos estos interrogantes con suma confianza y claridad, sosteniendo que este principio ha implicado, tradicionalmente, que las partes del proceso dispongan de los mismos derechos, oportunidades y cargas en función de la defensa de sus respectivos intereses porque, finalmente, las partes son iguales ante la ley, el juez o el árbitro o, al menos, su posición en el proceso es igual. De eso se trataría el principio de igualdad de las partes. ${ }^{14}$

Pero, ¿¿de eso se trata en realidad este principio?

En primer lugar, no es concebible hablar de igualdad de las partes o posición igualitaria de las partes en un proceso arbitral. Y la razón es muy simple. Porque si las partes fueran iguales o su posición fuera igual en el proceso, entonces no podría haber proceso alguno. Porque para que un proceso exista, precisamente las partes no pueden ser iguales. Si lo fueran, solo existiría una parte y por lo tanto una sola posición, lo que haría imposible el principio de dualidad de partes y dualidad de posiciones disidentes que dan vida en el proceso arbitral al principio de contradicción.

En este sentido, de lo que se trataría es más bien de que las partes tengan las garantías procesales necesarias para que puedan ejercer en toda su magnitud el principio de contradicción en el proceso arbitral. Esto es lo que conocemos como el debido proceso que es, precisamente, que se haga justicia, es decir, que el resultado del proceso expresado en un laudo determine que las partes no son jurídicamente iguales a ojos del árbitro. Y esto porque, contrariamente a lo que se suele afirmar, ${ }^{15}$ la esencia de la justicia no es la igualdad, sino la desigualdad frente

14 Ver Ana María Chocrón Giráldez, Los principios procesales del arbitraje..., 76.

15 En efecto. El principio de igualdad de las partes no sería sino una proyección del principio universal de igualdad ante la ley, cuyos orígenes se remontan a la Revolución Francesa. Las partes serían iguales ante el árbitro porque este encarna a la ley. Sin embargo, lo cierto es que la igualdad ante la ley no es más que una ficción jurídica por la cual se vuelve iguales a quienes, en la realidad del mundo, no lo son. Pero ya en el plano mismo de la ficción, el principio de igualdad ante la ley tiene grietas que la doctrina moderna debería poder resanar, si pretende que este edificio conceptual siga en pie. Porque, en efecto, ¿somos todos iguales ante la ley? ¿Son los menores de edad iguales que los mayores de edad ante la ley? ¿Son los condenados penales iguales que los inocentes ante la ley? ¿Son los militares —en el Perú al menos—iguales que los civiles 
al derecho en tanto que para el juzgador, una parte debe tenerlo y la otra no. Así pues, hacer justicia es declarar la desigualdad de los que creen tener iguales derechos.

Ahora bien, que la ley les otorgue a las partes las garantías necesarias para el ejercicio del principio de contradicción procesal tampoco implica que las partes deban recibir, con relación a estas garantías, un trato igualitario por el árbitro en el proceso. Porque, en efecto, para hallar quién de las dos partes tiene el derecho, no es infrecuente ni indeseable que el árbitro pueda - y deba - imponerle a una de ellas más cargas, más deberes y más obligaciones que a la otra. ${ }^{16}$ Contrario sensu, podría haber una parte que tenga menos cargas, menos deberes y menos obligaciones en el proceso. Esto significa que no existe ninguna garantía de que las partes deban ser tratadas con igualdad en el proceso. Así pues, la igualdad de las partes no puede ser concebida como una garantía procesal.

¿Qué es entonces lo que garantiza la ley a las partes de un proceso? No otra cosa que todos los medios o recursos procesales que la ley pone a disposición de cada una de las partes, para que estas los utilicen como crean conveniente. Y, como bien podrá adelantar el lector, ni estos medios o recursos procesales serán utilizados igualmente por las partes —cada una elegirá el que le interese-, ni los recursos son necesariamente iguales para ambas partes, sino que dependerán en algunos casos de la posición que ocupe cada una de ellas en el proceso arbitral. Así por ejemplo, a la parte actora le corresponderá demandar y a la que se opone le tocará contestar y, en su caso, reconvenir (contrademandar). De ahí que ni siquiera los recursos o medios procesales que la ley pone a disposición de las partes son iguales para ambas. ${ }^{17}$

Es cierto, al menos formalmente, que es en la cuestión de oportunidades procesales, esto es, de la libertad que tendrían las partes para elegir los recursos de uso común que la ley pone

ante la ley? ¿Es el Presidente de la República igual que Perico de los Palotes ante la ley? ¿Ante qué ley son iguales? ¿Ante la Ley de leyes? ¿Pero no es esta, acaso, la que reconoce estableciendo, precisamente, que ante ella estos sujetos no son iguales? Con estas preguntas no es nuestra intención desarrollar un debate doctrinario sobre el viejo principio de igualdad ante la ley en una obra sobre el arbitraje, cuando el debate debería canalizarse en algún ensayo de teoría del derecho. Solo hemos querido dejar establecido que incluso en el plano de la ficción jurídica, el principio de igualdad ante la ley y su carácter universal es un principio teóricamente discutible. Luego, su proyección en el proceso arbitral también.

16 "[...] El principio de igualdad procesal exige que las dos partes contrapuestas del proceso gocen de los mismos derechos y libertades y asuman las mismas obligaciones, cargas y deberes; y por ello no se atenta contra este esencial principio por el hecho de que una de las partes tenga que probar más extremos que la otra ajustándose a los principios que regulen la carga de la prueba que, no es ni puede ser atentatorio a este principio. Al contrario, la esencia del proceso puede exigir que una parte haya de probar más hechos que la contraria o que los medios de prueba que quiera utilizar puedan ofrecer para su práctica más dificultades que la otra [...]". Sentencia de la Audiencia Provincial de Madrid del 22 de septiembre de 1992. Ana María Chocrón Giráldez, Los principios procesales del arbitraje..., 76. (La cursiva es nuestra). Lo que a nuestro entender dice esta sentencia, más allá de las piruetas conceptuales, es que las partes pueden recibir un trato desigual en el proceso en aras de la misma justicia que se pretende encontrar.

17 Guasp considera que el principio de igualdad "no es una norma fundamental del proceso de manera directa, aunque puede serlo de un modo secundario, indirecto o reflejo". Jaime Guasp, "Administración de justicia y derechos de personalidad", Revista de Estudios Políticos, tomo IX (1944): 93. Fundamenta su posición al delimitar la igualdad jurídica, en la que no tienen por qué existir actitudes jurídicamente equivalentes entre el que pretende y el que se opone. 
a su disposición en el proceso, que el así llamado principio de igualdad de las partes cobraría mayor sentido. Empero, esto también es debatible. En primer lugar, habría que discutir si la igualdad atañe a las partes o a las oportunidades. Nos inclinamos por esta última hipótesis, porque que la ley otorgue oportunidades procesales a todos los que quieran hacer valer una pretensión en una corte de justicia o en un tribunal arbitral no significa que todos ellos sean iguales procesalmente hablando. $\mathrm{Y}$ esto porque de la igualdad de oportunidades no puede colegirse lógicamente la igualdad de los usuarios. Como hemos afirmado, es esa desigualdad frente al derecho que se pretende la que funda el proceso.

Así pues, de lo único que podemos estar seguros es de que el carácter absoluto del así llamado principio de igualdad de las partes en el arbitraje es, por las razones expuestas, bastante controvertido. Esta controversia nos lleva a interpretar, ya fuera de la tradición doctrinaria a todas luces insuficiente, el sentido que anima el susodicho principio. Pues que se hable de igualdad de las partes, de igualdad de oportunidades, de igualdad de derechos y obligaciones, de posiciones igualitarias, entre otras "igualdades" que sostiene la tradición deben animar el proceso arbitral $-y$, en realidad, cualquier proceso-, tiene por sentido último que las partes, por más desiguales que puedan ser en el proceso, según hemos podido constatar en los párrafos precedentes, no sean discriminadas en sus pretensiones por los árbitros.

Esto significa que durante el proceso y antes del laudo, esto es, cuando las partes contradicen ante el árbitro sus hechos y sus derechos, este no debe tomar partido por ninguna de ellas en desmedro de la otra. Y ello porque, aunque deba finalmente tomar partido en el laudo, pues para eso es árbitro, no puede hacerlo sin escuchar ni analizar las posiciones de ambas a través de todos los medios procesales que la ley les permite utilizar para tal fin. Lo que también quiere decir que no puede tomar partido impidiendo que una de las partes pueda ejercer plenamente el principio de contradicción procesal. Hacerlo significaría discriminar a las partes antes de lo que la ley permite, que es en el laudo donde se discrimina quién tiene el derecho y quién no. En este orden de ideas, cualquier discriminación anticipada no es más que un despropósito en tanto le quita todo sentido al proceso por el cual debe llegarse a la justicia.

De este modo podemos afirmar que el principio de igualdad procesal de las partes bien podría ser traducido por el más lógico y coherente principio de no discriminación de las partes en el proceso, que salvaría todas las objeciones teóricas al primero, rescatando su sentido final.

Por otra parte, también es importante señalar, en relación a lo dispuesto por el inciso 2 del artículo 34 del Decreto Legislativo $N^{\circ} 1071$, que suele ser práctica habitual en los procesos arbitrales, que cuando alguna parte por alguna razón especial solicita la prórroga de alguna fecha para la realización de alguna audiencia, el tribunal arbitral la considera y la estima pertinente. 
Esto, en estricto, podría ser considerado como una práctica inequitativa, en la medida en que se está favoreciendo a una parte para evitar que esa parte que solicita la prórroga de la fecha de la audiencia, precisamente, sufra un perjuicio o un problema; pero, en estricto, ante la convocatoria a una audiencia esa parte está debidamente notificada y tiene que tomar todas las previsiones para asistir.

Lo que ocurre es que esta práctica habitual de conceder esa prórroga para la fecha de audiencia, parte de la idea de que no se produzca luego la alegación de que se está afectando el derecho de defensa, por más de que se trate de una citación oportuna y con todas las condiciones de ley, para que no se señale que se está violentando ese derecho de defensa, ya sea porque la parte que solicita la prórroga no pueda asistir físicamente a la audiencia o que su abogado se encuentre impedido de asistir a ella o alguna otra circunstancia.

Entonces, si uno sopesa esas dos consideraciones, creemos que la inmensa mayoría de tribunales arbitrales, para tratar de llevar el arbitraje sin mayores inconvenientes o problemas, precisamente, conceden esas prórrogas.

Tales prórrogas se conceden en estricto respeto a este ejercicio del derecho de defensa y los tribunales arbitrales - por regla general y salvo casos muy excepcionales - no deberían aceptar que se produzca más de una (solicitada necesariamente por la misma parte en relación al mismo acto procesal), en la medida de que, precisamente, esa situación ya sería inequitativa en torno a la parte que no está solicitando dicha prórroga, y que tiene todo el derecho de que el proceso avance y se lleve a cabo la audiencia.

Además, se debe tener en cuenta que estas solicitudes reiteradas de postergación de audiencias pueden obedecer —en algunos casos - a maniobras dilatorias que los tribunales arbitrales deben sopesar en cada oportunidad.

Asimismo, lo dispuesto por el inciso 2 del artículo 34 de la Ley también mantiene relación con otro tema, y es que en los procesos arbitrales, generalmente y a diferencia de lo que ocurre con los procesos ordinarios, se presentan situaciones relativas a la posibilidad de que se otorgue un lapso mayor a las partes para hacer uso de la palabra en las audiencias.

Esta situación es práctica común en los tribunales arbitrales y se explica en razón de la especial naturaleza del proceso, dado que los árbitros son personas que no tienen la carga procesal de un juez ordinario, y en razón — también - de que en los arbitrajes trata de buscarse la verdad, por todos los medios ajustados a ley y a las normas del proceso.

De tal manera que no es inusual —al contrario, es práctica corriente- que en los tribunales arbitrales la intervención de las partes no dure, como en los tribunales ordinarios, cinco o diez minutos, sino por el contrario, dure media o una hora y que los derechos de 
réplica, dúplica, intervenciones adicionales, preguntas del tribunal, etc., hagan que se puedan exponer de manera extensa las posiciones de cada parte, con lo que el tribunal podrá tener mayores herramientas para dilucidar la controversia y, además, hacerse una idea cabal del tema, debido a que cuenta con todas las posibilidades de preguntar y de repreguntar en las respectivas audiencias.

En adición a lo expuesto, puede decirse que ese ejercicio de los derechos es un ejercicio irrestricto en las audiencias, en la medida de que las partes puedan ser asistidas, no solo por uno, sino por varios abogados; pueden intervenir peritos, para que también informen, ingenieros y especialistas en otras materias que no sean necesariamente jurídicas. Además, los tribunales arbitrales suelen, cuando las materias son muy complejas, convocar a actuaciones adicionales para que puedan expresarse las partes con toda libertad, informando sobre las posiciones que cada una tiene sobre determinados puntos controvertidos, con la asistencia de sus asesores, peritos, abogados, etc.

De tal manera, todas estas actuaciones que forman parte, sin duda, del principio de flexibilidad del arbitraje y que no vulneran el desarrollo correcto del mismo deben ser prácticas que siempre mantengan una igualdad de trato para las partes involucradas.

Caso contrario, vale decir que en la medida en que esa igualdad de trato se vulnere, también se estará vulnerando el debido proceso y, por lo tanto, se estaría dejando la puerta abierta para que el laudo que emita el tribunal arbitral pueda ser anulado.

El inciso 3 del artículo 34 señala que si no existe disposición aplicable en las reglas aprobadas por las partes o por el tribunal arbitral, se podrán aplicar de manera supletoria las normas del Decreto Legislativo No 1071.

Asimismo, establece que si no existe norma aplicable en el Decreto Legislativo No 1071, el tribunal arbitral puede recurrir, según su criterio, a los principios arbitrales, así como a los usos y costumbres en materia arbitral.

Esta norma resulta muy importante, porque evidentemente los convenios arbitrales y tampoco las actas de instalación van a requerir el que se produzca de manera explícita un desarrollo amplio de todos los puntos o reglas del proceso, en la medida en que supletoriamente se tendrá un reglamento arbitral en el caso de los arbitrajes institucionales, o del Decreto Legislativo No 1071, en el caso de los arbitrajes ad hoc.

En ambos casos, la Ley de Arbitraje constituye norma de aplicación supletoria.

Ahora bien, es evidente que dentro de la lógica de marcar diferencias notorias entre los procesos arbitrales y los procesos ordinarios, no se señala dentro de la Ley de Arbitraje la supletoriedad de aplicación de normas del Código Procesal Civil. 
Fundamentalmente existe, y eso uno lo aprecia en algunos árbitros, el temor de que el arbitraje se judicialice con la aplicación supletoria de normas del Código Procesal Civil.

Estimamos que estos temores no son necesariamente fundados, en la medida en que las partes no pueden hacer uso de recursos ajenos a aquellos que establece la Ley de Arbitraje, el reglamento arbitral que fuere aplicable y el acta de instalación. Es decir, las partes no pueden traer al proceso arbitral los recursos propios de un proceso civil.

Sin embargo, no nos extraña la posibilidad de hacer de aplicación supletoria al arbitraje algunos principios del derecho procesal civil que han merecido un desarrollo pormenorizado por la doctrina procesal de la tradición jurídica romano-germánica.

Creemos que la doctrina arbitral en lo fundamental se ha ocupado del proceso arbitral, pero no necesariamente se ha detenido a estudiar temas que han sido desarrollados de manera profunda y concienzuda por la doctrina procesal civil.

Un ejemplo claro lo encontramos en lo relativo a la valoración de las pruebas.

No olvidemos que existen muchos tratados sobre la materia en todos los países de la tradición jurídica romano-germánica.

Cómo se aprecia una prueba, cómo se aprecia una pericia, cómo se aprecia una inspección sea esta judicial o arbitral, cómo se aprecia la prueba de testigos, cómo se aprecia un documento público o un documento privado, qué valor se le da, etc., son temas no desarrollados usualmente por la doctrina arbitral. Cabe señalar que tampoco son desarrollados por las leyes de arbitraje $^{18}$ y no merecen tratamiento especial en las normas contenidas en las actas de instalación ni en los convenios arbitrales que celebran las partes.

Entonces, ¿cómo debe ser apreciada una prueba? ¿Qué sustento puede tener el tribunal arbitral, a efectos de considerar una prueba en un laudo o al resolver un incidente o una excepción?

La valoración de la prueba es un tema que pertenece a la doctrina procesal civil y creemos que en esta materia sí resultan de aplicación supletoria los principios recogidos por el Código Procesal Civil.

18 En el caso peruano, el Decreto Legislativo $N^{\circ} 1071$ solo hace una breve mención en torno a la relación de la prueba, cuando en el artículo 43 señala:

Artículo 43.- Pruebas

1. El tribunal arbitral tiene la facultad para determinar de manera exclusiva la admisión, pertinencia, actuación y valor de las pruebas y para ordenar en cualquier momento la presentación o la actuación de las pruebas que estime necesarios.

2. El tribunal arbitral está facultado asimismo para prescindir motivadamente de las pruebas ofrecidas y no actuadas, según las circunstancias del caso. 
De esta forma, creemos que resultaría de suma importancia realizar un estudio a efectos de analizar qué instituciones o qué figuras del Código Procesal Civil pudieran aplicarse de manera supletoria al arbitraje. ${ }^{19}$

Pensamos que no hay que tener miedo sobre eso y, evidentemente, cuando nosotros hablamos de aplicación supletoria, no lo hacemos respecto a la aplicación supletoria estricta de la norma. Esto resulta impensable, porque hay muchos casos en los cuales ello sería imposible, en la medida de la distinta naturaleza que tiene un proceso arbitral con un proceso ordinario.

A lo que nos estamos refiriendo es a la aplicación supletoria de los principios que inspiran esas normas de derecho procesal civil y que se encuentran materializadas en el Código adjetivo, que es el Código Procesal Civil. No debemos tener miedo a eso, porque en lugar de entorpecer el arbitraje, esa supletoriedad enriquece las instituciones arbitrales y es que se trata de materias que, dada la relativa juventud del arbitraje comercial en el mundo moderno y su reciente desarrollo, la doctrina arbitral no se ha ocupado - y probablemente no se ocupede esos temas en los diferentes libros y artículos que se escriben sobre el particular.

Ello es así, además, porque se trata de materias que ya han sido lo suficientemente desarrolladas y cuyo tratamiento y aplicación, sin duda, la doctrina arbitral no rechaza ni recusa por el simple hecho de que fueron desarrolladas por especialistas en procesos ordinarios civiles y no por especialistas en procesos arbitrales.

Por otro lado, el inciso 4 del artículo 34 de la Ley de Arbitraje, bajo estudio, establece que el tribunal arbitral podrá, a su criterio, ampliar los plazos que haya establecido para las actuaciones arbitrales, incluso si estos plazos estuvieran vencidos.

Lo contenido en dicho numeral refleja el principio de flexibilidad que, a diferencia de un proceso ordinario, vigoriza la práctica arbitral. ${ }^{20}$

19 De hecho, no hace mucho, en junio del año 2011, Lizbeth Panduro Meza, estudiante egresada de la Facultad de Derecho de la Pontificia Universidad Católica del Perú, obtuvo el título profesional de abogado con una tesis sobre este tema, titulada Aplicabilidad de las instituciones procesales en el arbitraje.

20 La flexibilidad del arbitraje se conceptualiza, en primer término, con el propósito de establecer una diferencia entre la rigidez de los procesos de la justicia ordinaria y los procesos arbitrales. Como se recuerda, el Código Procesal Civil peruano y, en general, los códigos de procedimientos civiles en el mundo, establecen términos y procedimientos cuyas normas tienen carácter de orden público, es decir, que, salvo casos absolutamente excepcionales, las partes no pueden disponer algo distinto con respecto a tales disposiciones. Por el contrario, la Ley de Arbitraje y, en general, las leyes arbitrales del mundo, si bien contienen grupos de normas de carácter imperativo, como por ejemplo las relativas a la materia arbitrable, también comprenden otras muchas de carácter dispositivo, con respecto a las cuales las partes pueden establecer disposiciones particulares, incluso apartándose del texto de la propia ley. La idea general en el arbitraje es que las partes puedan establecer las normas que rijan el proceso, amoldando sus etapas y desarrollo a sus propios intereses. Tratándose de una justicia privada, va implícito en el concepto del arbitraje esa libertad que tienen las partes para autorregular el proceso, de la manera que consideren más conveniente para resolver sus conflictos. 
Sin embargo, estimamos que la peculiar norma debe merecer una lectura mejorada y razonable, en el sentido de situarla fuera de la arbitrariedad y la contravención al debido proceso. Pero, debemos admitir que ello resultará bien difícil.

Nos explicamos.

El citado inciso 4 del artículo 34 de la Ley de Arbitraje se refiere a la posibilidad de ampliar o modificar plazos por vencer o ya vencidos.

Para el desarrollo de este tema no hay que olvidar que el acta de instalación del tribunal arbitral no solo es una etapa o acto procesal del arbitraje, sino, además, un acto de naturaleza contractual, en el cual las partes y los árbitros manifiestan su consentimiento en torno a las reglas que regirán el proceso arbitral al que están dando inicio.

Este establecimiento de reglas especiales representa un acto de consenso. Entendemos que no debe presumirse que las partes hubiesen dado ese consentimiento si se les hubiese propuesto regular sus disposiciones en sentido diverso.

Es decir, no hay que partir de la idea de que, por ejemplo, un plazo convenido por treinta días, igualmente favorezca a las partes si fuese de quince o de cinco. No en vano se han pactado treinta.

Además, las partes tienen todo el derecho de hacer sus previsiones y diseñar su estrategia procesal en razón de los plazos establecidos en el acta de instalación, los mismos que son de conocimiento recíproco de las partes y del propio tribunal, y a cuyo cumplimiento se han obligado las partes y los árbitros.

Entendemos que dentro de una sana concepción del principio de flexibilidad, con relación a los plazos pactados en el acta de instalación, un tribunal arbitral podría proponer a las partes, por ejemplo, la ampliación del plazo establecido para el término de actuación de pruebas, o la ampliación de los términos pactados para expedir el laudo arbitral, contado desde la resolución de "tráigase para laudar".

En tales casos, si el tribunal contara con la aceptación de ambas partes, podrá proceder a la modificación o ampliación de dichos plazos, en la medida de que todos quienes intervienen en el proceso estarían dando su consentimiento para modificar los términos de un contrato previo, aquel que tuvo lugar con el acta de instalación del tribunal arbitral.

Por el contrario, entendemos que ni las partes puestas de acuerdo ellas mismas podrían imponer al tribunal arbitral un cambio en las reglas del proceso, sin contar con el asentimiento del propio tribunal. 
Del mismo modo, suena lógico que el tribunal arbitral no pueda variar, motu proprio, las reglas del proceso, sin contar con el asentimiento de ambas partes.

Este tema resulta doblemente importante en lo que a plazos se refiere, en la medida de que buena parte de las normas que rigen un proceso son las relativas a los términos que regulan las distintas etapas procesales.

Y una lectura literal del inciso 4 del artículo 34 de la Ley de Arbitraje podría llevar a la equivocada interpretación de que el tribunal arbitral puede, de manera unilateral, hacer lo que considere más conveniente con respecto a los plazos que rigen el proceso arbitral.

Un ejemplo claro sería el siguiente: el acta de instalación del tribunal arbitral ha previsto diez días para interponer la demanda y diez días para contestarla. La parte demandante interpone su demanda el día décimo tercero. Como es lógico, el tribunal debería rechazar la interposición de dicha demanda por extemporánea, en la medida de que la misma se interpuso tres días después de vencido el término establecido en el acta de instalación.

Pensamos que constituiría un error sostener la licitud de que el tribunal arbitral admita a trámite dicha demanda y, por una mal entendida equidad, otorgue a la parte demandada un plazo de trece días para contestar la demanda y reconvenir, si así lo considerase conveniente.

Por añadidura, si ese tribunal arbitral actuara de este modo, seguramente se cuidará de dejar establecido que con la ampliación del plazo en tres días está tratando a las partes con igualdad, a la par que está otorgando a cada una de ellas suficiente oportunidad para hacer valer sus derechos; todo ello, en aparente estricto cumplimiento de lo dispuesto por el inciso 2 del artículo 34 de la Ley de Arbitraje.

Es lamentable que el inciso 4 del referido artículo 34 establezca estas facultades para los tribunales arbitrales, en relación a los plazos, pues ya se han visto casos de árbitros que actúan de esta manera, convencidos de que su accionar está ajustado a ley.

No obstante, si un tribunal arbitral procediese de esta forma, podrían ocurrir dos cosas.

La primera de ellas es que la parte demandada no interponga recurso de reconsideración alguno contra la resolución que le corre traslado de la demanda extemporánea y proceda a contestarla. En este caso, será obvio que la parte demandada estará aceptando tácitamente la ampliación del plazo y estará aceptando también que dicha ampliación no afecta sus intereses como parte en el proceso.

Sin embargo, como es de presumir, la casi totalidad de partes demandadas que se encontraran en una situación como esta, no procederían de esa forma, ya que interpondrían recurso de reconsideración contra dicha resolución, a efectos de que el tribunal la revoque de 
inmediato y proceda a archivar el proceso, al no haberse interpuesto la demanda dentro del plazo establecido en el acta de instalación del tribunal arbitral.

¿Podría acaso el tribunal arbitral declarar infundado el recurso de reconsideración, invocando las facultades del inciso 4 del artículo 34, así como el trato equitativo que impone el inciso 3 del mismo artículo?

Consideramos que la respuesta negativa se impone, en la medida de que dicha modificación de plazo sí afecta los intereses de una de las partes, pues al demandado no le dará lo mismo tener tal condición en un proceso o liberarse de la calidad de demandado, con el archivo del expediente; situación que, incluso, podría beneficiarle, definitivamente, si es que hubiesen vencido los plazos de caducidad o de prescripción que la ley, eventualmente, concediera para la interposición de esas demandas.

Por otra parte, debemos recordar también que las normas de la Ley de Arbitraje, por más de que muchas de ellas hayan prescindido en su concepción de una necesaria relación con los demás cuerpos legales aplicables al caso, no pueden prescindir —en su aplicación— de una adecuada armonía con el resto del ordenamiento jurídico nacional.

Así, por más de que la norma arbitral (nos referimos al inciso 4 del artículo 34 de la Ley) diga lo que dice, los tribunales arbitrales no están facultados para actuar con la más absoluta libertad al respecto, en la medida de que las reglas establecidas en el acta de instalación, constituyen materia contractual, y su modificación pasa, como lo hemos dicho, por un contrato modificatorio en el que intervengan todas las partes que celebraron el contrato primitivo.

De otro lado, no hay que olvidar que el arbitraje, por más flexibilidad que tenga, no puede prescindir de los principios básicos que el Derecho Procesal Civil ha construido y desarrollado en torno al concepto del debido proceso, el mismo que también está recogido como derecho constitucional por nuestra Carta Política de 1993.

Si se incluyó el inciso 4 del artículo 34 en la Ley de Arbitraje, no dudamos de que ello obedeciera a las mejores intenciones. Sin embargo, un uso de esta norma que contravenga los principios básicos del derecho de contratos, los principios básicos del debido proceso y los principios básicos del derecho constitucional relativos al mismo, no contribuirá al desarrollo y progreso del arbitraje, sino a su envilecimiento, haciendo proliferar los recursos de anulación de los laudos arbitrales.

Y no hay que olvidar que una buena norma procesal es aquella que garantiza la equidad y la justicia, tanto en manos de un excelente tribunal arbitral, como empleada por un tribunal que no revista tales características profesionales y éticas. 
El uso y abuso del inciso 4 del artículo 34 puede constituir uno de los gérmenes del deterioro del arbitraje en el Perú.

En conclusión, la variación o ampliación de plazos nunca se deberá realizar en perjuicio de los derechos de una parte y en beneficio de otra, así como tampoco contraviniendo lo expresamente establecido en el convenio arbitral ni en el acta de instalación del tribunal. Ello, porque estamos ante actos contractuales en donde las partes han manifestado su voluntad con respecto a determinadas reglas, cuya variación requeriría de un nuevo consentimiento de las mismas.

\section{REFERENCIAS}

- Castillo Freyre, Mario y Ricardo Vásquez Kunze. Arbitraje. El juicio privado: la verdadera reforma de la Justicia. Biblioteca de Arbitraje del Estudio Mario Castillo Freyre. Lima: Palestra Editores-Estudio Mario Castillo Freyre, 2006, vol. 1.

- Chocrón Giráldez, Ana María. Los principios procesales del arbitraje. Barcelona: J. M. Bosch Editor, 2000.

- García Calderón Moreyra, Gonzalo. El arbitraje internacional. Lima: Cecosami, 2004.

- González de Cossío, Francisco. Arbitraje. México: Editorial Porrúa, 2008.

- Guasp, Jaime. "Administración de justicia y derechos de personalidad". Revista de Estudios Políticos. T IX (1944).

- Kundmüller Caminiti, Franz. "Inicio del arbitraje". En Comentarios a la ley peruana de arbitraje. Lima: IPA, 2011, tomo I.

- Kundmüller Caminiti, Franz. "Libertad de regulación de actuaciones". En Comentarios a la ley peruana de arbitraje. Lima: IPA, 2011, tomo I.

- Montero Aroca, Juan. Introducción al Derecho Procesal. Madrid: Ediciones Tecnos, 1976.

- Vidal Fernández, Begoña. "Inicio del arbitraje". En Comentarios prácticos a la Ley de Arbitraje. Valladolid: Editorial Lex Nova, 2004.

- Yánez Velasco, Ricardo. Comentarios a la nueva Ley de Arbitraje. Valencia: Tirant lo Blanch, 2004.

Recibido: $24 / 10 / 16$

Aceptado: 21/11/16 


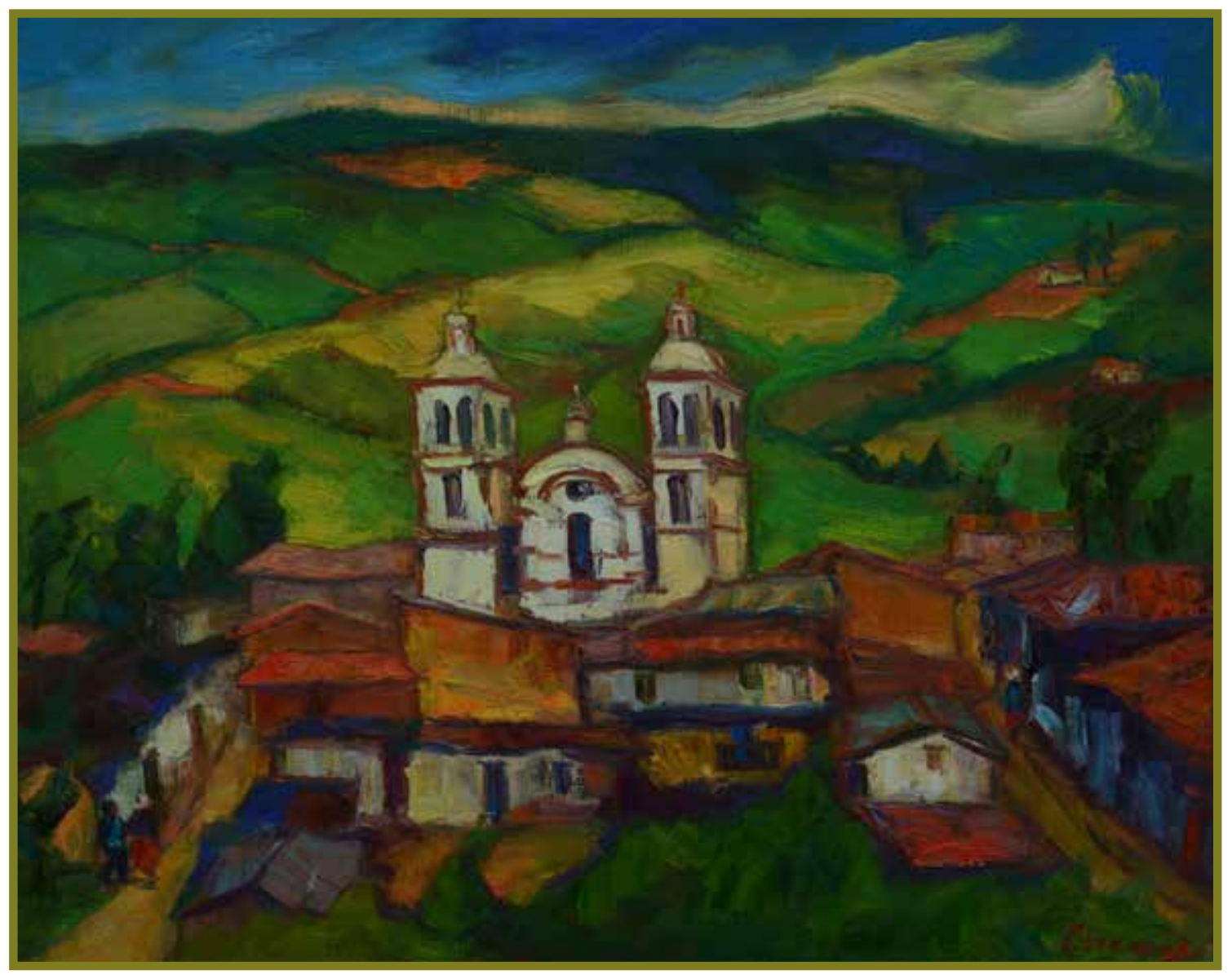

Llapa. Óleo sobre lienzo $(65 \mathrm{~cm}$ x $81 \mathrm{~cm})$. Ever Arrascue. 